(2) Open Access Full Text Article

\title{
Investigation of in vivo potential of scorpion venom against skin tumorigenesis in mice via targeting markers associated with cancer development
}

This article was published in the following Dove Press journal:

Drug Design, Development and Therapy

18 October 2016

Number of times this article has been viewed

\author{
Abdulrahman K Al Asmari \\ Abdul Quaiyoom Khan \\ Research Centre, Prince Sultan \\ Military Medical City, Riyadh, \\ Saudi Arabia
}

\begin{abstract}
Cancer is the leading cause of morbidity and mortality all over the world in spite of the advances made in its management. In this study, we investigated the in vivo antitumorigenic potential of the venom obtained from a medically important scorpion species Leiurus quinquestriatus on chemically induced skin cancer in mice. Animals were divided into five groups, with 13 animals in each group. All the treatments were given topically on the shaved dorsal surface of the skin. Animals in Group 1 received vehicle only $(0.2 \mathrm{~mL}$ acetone). Moreover, 7,12-dimethylbenz[a]anthracene (DMBA, $400 \mathrm{nmol}$ per mouse) was applied to all the animals in the remaining four groups. After 1 week, different concentrations of venom $(17.5 \mu \mathrm{g}, 35 \mu \mathrm{g}$, and $52.5 \mu \mathrm{g}$ per animal) were applied to each animal in the Groups III-V. Thirty minutes after the application of venom, croton oil was applied on the same position where venom was administered to the animals of Groups III-V. Animals in Group II were treated as the positive control (without venom) and received croton oil as in Groups III-V. The findings of this study revealed that venom extract of L. quinquestriatus inhibits DMBA + croton oil-induced mouse skin tumor incidence and tumor multiplicity. Venom treatment also decreased the expression of proinflammatory cytokines. Immunohistochemistry results showed a downregulation of the expression of molecular markers such as Ki-67, nuclear factor kappa-B, cyclooxygenase-2, B-cell lymphoma-2, and vascular endothelial growth factor, in venom-treated animals. Our findings suggest that the venom of L. quinquestriatus possesses in vivo anticancer potential and may be used in the development of anticancer molecules.
\end{abstract}

Keywords: Leiurus quinquestriatus, skin cancer, apoptosis, immunosuppression

\section{Introduction}

Cancer is a leading cause of death worldwide, and according to a recent global survey, 14.1 million new cancer cases and 8.2 million deaths due to cancer were recorded in $2012 .{ }^{1}$ Radiation therapy, chemotherapy, immunotherapy, surgery, and hormonal therapy are the available options for the treatment of cancer patients. ${ }^{2,3}$ However, these measures are inadequate for the management of cancer due to severe adverse effects and many other issues associated with therapy.

A number of efforts have been made for the development of an alternative and effective therapeutic approach for cancer management. Various studies show that attention is being given to naturally derived products for the development of novel and effective chemotherapeutic drugs. ${ }^{4,5}$ The therapeutic importance of biological products in the mitigation of different chronic human diseases, including cancer, has been well documented. .,6 $^{5}$
Correspondence: Abdulrahman K Al Asmari

Research Centre, Prince Sultan Military Medical City, PO Box 7897 (777-S),

Riyadh III59, Saudi Arabia

Tel +966 II $47777 \mid 4$ ext 25100

Fax +966 I| 478 660 I

Email abdulrahman.alasmari@gmail.com 
Various findings clearly show that toxins derived from living organisms have strong anticancer potential. ${ }^{7-11}$ Natural toxins produced by living organisms are an evolutionary adaptation to sustain in the food chain. Such toxins play a vital role in defense/offence and in catching of prey. It is well established that in spite of their toxicity, toxins have important pharmacologically active moieties that can act as novel and effective therapeutics.

Scorpion is one of most primitive organisms known to exist on the earth for millions of years and is distributed all over the world, with $>1,700$ known species. ${ }^{12}$ Numerous scorpion species $(>25)$ have been identified in different regions of Saudi Arabia. ${ }^{13}$ Scorpion venom is a mixture of different types of biologically active components, such as peptides and proteins, mucopolysaccharides, phospholipases, hyaluronidases, protease inhibitors, serotonin, histamine, histamine-releasing peptides, nucleotides, inorganic salts, mucus, free amino acids, lipids, heterocyclic components, many basic small proteins called neurotoxic peptides, and many other unknown components. Biochemical characterization of scorpion venom has shown that it is composed of peptides and proteins of 60-70 amino acid residues, which are cross-linked by disulfide bridges. ${ }^{14,15}$ All the known species of scorpions produce different type of venoms containing different toxic polypeptides with similar three-dimensional

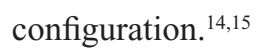

In spite of the negative impact of scorpions on the human population, these arthropods and their venom have been extensively used in the traditional medical systems and folk therapies of India, Africa, and China since thousands of years. ${ }^{16,17}$

Various findings have shown that the components of scorpion venom have strong antibacterial, antifungal, and antiviral potential. ${ }^{18-23}$ Furthermore, a number of preclinical (in vitro and in vivo) and clinical research findings have demonstrated that scorpion venom and its components possess remarkable anticancer potential against different types of cancers, including glioma, neuroblastoma, leukemia, lymphoma, as well as breast, lung, and prostate cancers, due to their apoptotic, antiproliferative action coupled with the induction of cell cycle arrest and inhibition of cancer progression., ${ }^{911,24}$ The venom of Leiurus quinquestriatus is a mixture of various components, such as enzymes, enzyme inhibitors, and the potent neurotoxins chlorotoxin, charybdotoxin, and so on. Chlorotoxin is known to inhibit cancer development. Available literature about the importance of venom in disease therapy motivated us to select L. quinquestriatus venom for study.
Considering these known facts, this study was designed to investigate the in vivo anticancer potential of the crude venom extracted from the scorpion L. quinquestriatus, collected from various regions of Saudi Arabia, against chemically induced two-stage skin cancer development in Swiss albino mice. To the best of the authors' knowledge, this is the first study that demonstrates the in vivo anticancer potential of L. quinquestriatus scorpion venom against skin tumorigenesis in mice.

\section{Materials and methods Chemicals and reagents}

7,12-Dimethylbenz[a]anthracene (DMBA), croton oil, potassium dihydrogen phosphate, dipotassium hydrogen phosphate, sodium chloride, Tris (hydroxymethyl) aminomethane, and Tween 20 were purchased from SigmaAldrich (St Louis, MO, USA). All other reagents used were of analytical grade.

\section{Scorpion and venom collection}

L. quinquestriatus, one of the medically important scorpion species, was collected from various regions of Saudi Arabia. They were kept in plastic boxes and fed with mealworms and water ad libitum. Venom was milked by electrical stimulation using the 6012 Dual Pulse Stimulator (Harvard Apparatus, Holliston, MA, USA). The recovery of venom was achieved by mixing it with distilled water, followed by centrifugation at $10,000 \mathrm{rpm}$ for 10 minutes. The supernatant thus obtained was lyophilized and stored at $-80^{\circ} \mathrm{C}$ until use. Concentrated venom stock was prepared in phosphatebuffered saline and sterilized by passing through a $0.22 \mu \mathrm{m}$ membrane filter. Further dilutions were made as required for the experiments.

\section{Animals}

Male Swiss albino mice (20-25 g) were obtained from the animal house facility of Research Centre, Prince Sultan Military Medical City, Riyadh, Saudi Arabia. All the animals were housed in the animal care facility under room temperature at $22^{\circ} \mathrm{C}-25^{\circ} \mathrm{C}$ under a 12 -hour light/12-hour dark cycle in standard cages and were given free access to standard laboratory diet and water ad libitum. This study was conducted in strict accordance with the guidelines and recommendations of the Guide for the Care and Use of Laboratory Animals published by the National Institutes of Health. The study was approved by the ethics committee on the Use of Experimental Animals of the Research Centre, Prince Sultan Military Medical City. Animals were monitored daily for any sign of toxicity, tumor bleeding, and mortality 
throughout the experimental period. No signs of toxicity, tumor bleeding, and mortality were observed during the regular monitoring of the animals. Animals were euthanized by cervical dislocation under diethyl ether anesthesia for dissection and collection of skin tissue, and all efforts were made to minimize suffering.

\section{Treatment regimen}

The anticarcinogenic potential of the crude venom extract obtained from L. quinquestriatus was evaluated using the classic DMBA/12-O-tetradecanoylphorbol-13-acetate or croton oil-induced two-stage mouse skin carcinogenesis model. ${ }^{25,26}$ Animals were divided into five groups of 13 animals each. The dorsal skin of each animal was shaved with an electric clipper 2 days prior to initiation of the experiment. All the treatments were given topically onto the shaved area on the dorsal surface of the body. Animals of Group I were given topical application of vehicle $(0.2 \mathrm{~mL}$ acetone $)$ only. Animals in Group II-Group V were given topical application of DMBA (400 nmol) dissolved in $0.2 \mathrm{~mL}$ acetone. One week after DMBA application, croton oil (1\%) in $0.2 \mathrm{~mL}$ acetone was given twice a week for 16 consecutive weeks to the animals in Groups II-V. Venom extract of L. quinquestriatus at three different concentrations $(17.5 \mu \mathrm{g}, 35 \mu \mathrm{g}$, and $52.5 \mu \mathrm{g}$ per mouse) in $0.2 \mathrm{~mL}$ acetone was applied to the animals of groups III-V, respectively, 30 minutes prior to each croton oil application (twice a week) until the termination of the experiment at 16 weeks.

\section{Tissue collection and processing}

Animals were euthanized by cervical dislocation under diethyl ether anesthesia for dissection and collection of skin tissue. A portion of the skin tissue was stored in $10 \%$ neutral-buffered formalin for histological analysis, and the remaining tissue was immediately stored at $-80^{\circ} \mathrm{C}$ for the analysis of other parameters.

\section{Measurement of tumor necrosis factor alpha and interleukins $I \beta$ and 6}

The levels of tumor necrosis factor alpha (TNF- $\alpha$ ), interleukin (IL)-1 $\beta$, and IL-6 were measured using enzymelinked immunosorbent assay kits (Abcam, Cambridge, UK; ab100747, ab100713, and ab100705, respectively). Skin tissues were homogenized in extraction buffer (100 mM Tris $\mathrm{pH}$ 7.4, $150 \mathrm{mM} \mathrm{NaCl}, 1 \%$ Triton X-100), and the homogenate was centrifuged at a speed of $14,000 \mathrm{rpm}$ at $4^{\circ} \mathrm{C}$ for 30 minutes to obtain the tissue lysate. Further processing was performed according to the manufacturer's instruction.
Results in picograms per milliliter were normalized to the tissue weights determined before homogenization and are presented as picograms per milligram tissue.

\section{Immunohistochemical detection of Ki-67, nuclear factor kappa-B p65, cyclooxygenase-2, B-cell lymphoma-2, and vascular endothelial growth factor expression}

Skin sections ( $5 \mu \mathrm{m}$ thickness) were mounted onto polyL-lysine-coated glass slides. Sections were deparaffinized three times ( 5 minutes each) in xylene, followed by rehydration in graded ethanol, and finally in running tap water. For antigen retrieval, the sections were boiled in $10 \mathrm{mM}$ citrate buffer ( $\mathrm{pH}$ 6.0) for 10 minutes. Next, the sections were incubated with Protein Block (Abcam) for 10 minutes at room temperature, followed by washing with Tris-buffered saline-Tween. Normal goat serum (ab138478) was used as the blocker for 2 hours prior to exposure to primary antibodies (Ki-67 [ab21700], nuclear factor kappa-B [NF- $\mathrm{KB}]$ p65, [ab27182], cyclooxygenase [COX]-2 [ab21704], B-cell lymphoma [Bcl]-2 [ab7973], and vascular endothelial growth factor [VEGF; ab15295]) and sections were incubated at $4^{\circ} \mathrm{C}$ overnight. Further processing was done by using Mouse and Rabbit Specific HRP Plus (ABC) Detection IHC kit (ab93697; Abcam). The peroxide complex was visualized using 3,3-diaminobenzidine. Finally, the slides were counterstained with hematoxylin and cleaned in water, xylene, and ethanol. After dibutylphthalate polystyrene xylene (DPX) mounting, microscopic (BX53 microscope; Olympus Corporation, Tokyo, Japan) analysis was performed.

\section{Tumor incidence and tumor multiplicity}

Tumor incidence was evaluated by calculating the percentage of mice with one or more confirmed tumors. Tumor multiplicity was assessed by dividing the total number of tumors observed grossly with the total number of tumor-bearing mice.

\section{Histological analysis}

For histopathological studies, a portion of skin tissue was fixed in freshly prepared $10 \%$ neutral-buffered formalin. The tissue was embedded in paraffin wax, and blocks were prepared. Sections of $5 \mu \mathrm{m}$ thickness were mounted onto poly-L-lysine-coated microscopic slides and stained with hematoxylin and eosin. Images were captured on a microscope (BX53 microscope; Olympus Corporation, Tokyo, Japan) at 4x, 10x and 20x magnifications. 


\section{Statistical analysis}

The data are presented as mean \pm standard error of the mean. Differences between groups were analyzed using one-way analysis of variance, followed by the Tukey-Kramer multiple comparisons test. Data were considered statistically significant when the $P$-values were $<0.05$.

\section{Results}

\section{Effect of $L$. quinquestriatus venom on} tumor incidence, tumor multiplicity, and tumor histopathology in DMBA-initiated and croton oil-promoted mouse skin tumorigenesis

Application of L. quinquestriatus venom resulted in the suppression of tumor incidence and tumor multiplicity (Figure 1, Table 1). In Group II animals, a tumor incidence of $100 \%$ was observed and the tumor multiplicity was 14 .
Topical application of L. quinquestriatus venom in the antipromotion experimental animals (Group III-Group V) suppressed the tumor incidence as well as tumor multiplicity, compared to the results in Group II. Compared to a $100 \%$ tumor incidence in Group II, tumor incidence was $76.9 \%$ in the animals of Group III, accounting for $23.1 \%$ inhibition. On the other hand, $84.6 \%$ of animals in Group V developed tumors, with a $15.4 \%$ inhibition in tumor incidence, while least $(7.7 \%)$ reduction in tumor incidence was observed in Group IV animals (Table 1). L. quinquestriatus venom application resulted in the reduction of gross tumor multiplicity in the antipromotion experimental groups (III-V), compared to the Group II animals (Table 1).

Histological observations revealed that vehicle-treated Group I animals showed a normal pattern of skin epidermal and dermal layers, with mild or no infiltration of inflammatory cells (Figure 2A). DMBA-croton oil-treated Group II animals exhibited massive changes in both epidermal and
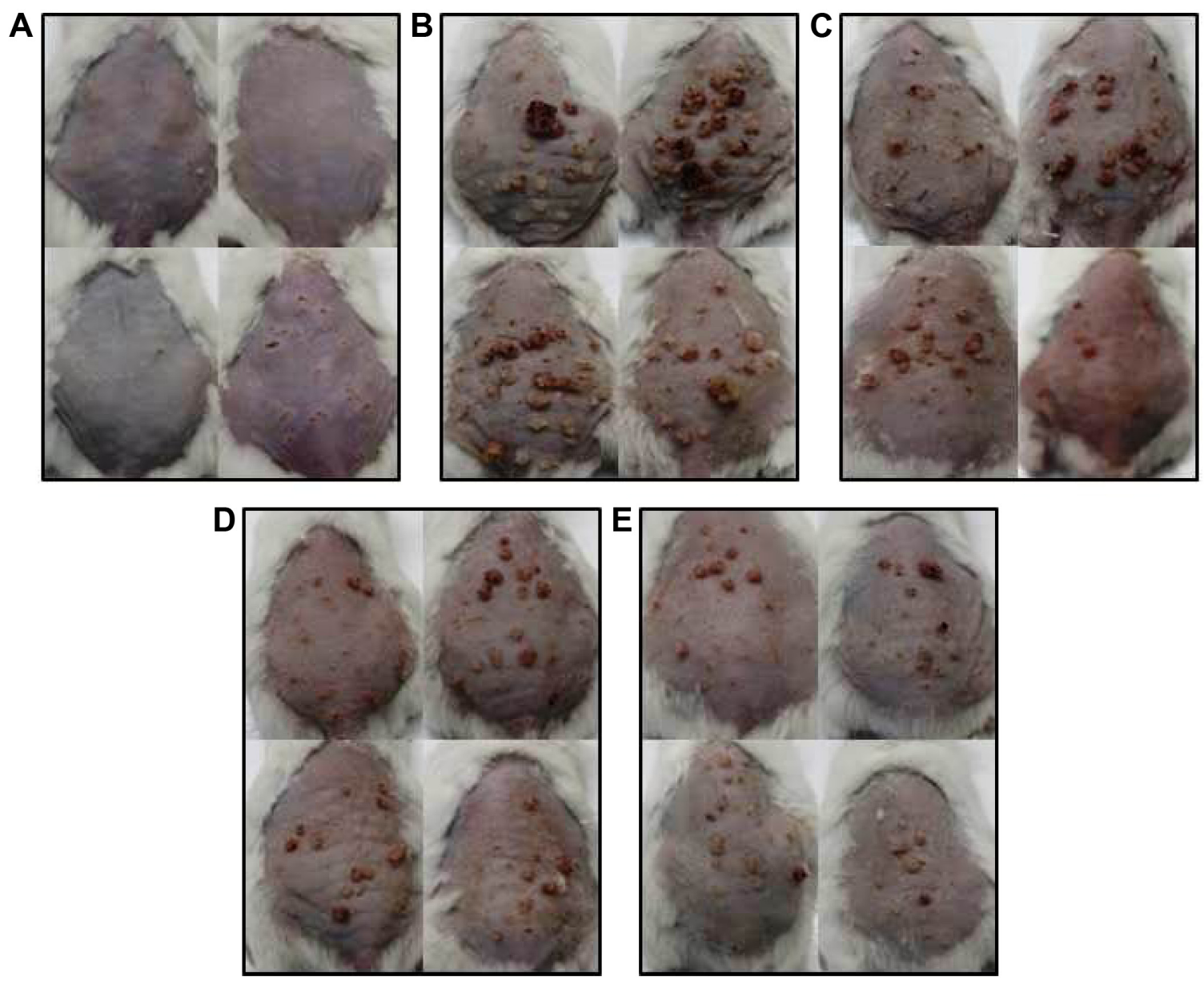

Figure I Effect of Leiurus quinquestriatus venom extract on DMBA/croton oil-induced mouse skin tumorigenesis.

Notes: (A) Group I: only vehicle (0.2 mL acetone); (B) Group II: DMBA + croton oil; (C) Group III: DMBA + croton oil + L. quinquestriatus venom (I7.5 $\mu \mathrm{g}$ per mouse); (D) Group IV: DMBA + croton oil + L. quinquestriatus venom (35 $\mu \mathrm{g}$ per mouse); and (E) Group V: DMBA + croton oil + L. quinquestriatus venom (52.5 $\mu \mathrm{g}$ per mouse). Abbreviation: DMBA, 7,I2-dimethylbenz[a]anthracene. 
Table I Effect of $L$. quinquestriatus crude venom extract on DMBAinitiated and croton oil-promoted mouse skin tumor incidence and tumor multiplicity

\begin{tabular}{lllll}
\hline Groups & $\mathbf{n}^{\mathbf{a}}$ & $\begin{array}{l}\text { Number of tumor- } \\
\text { bearing mice }\end{array}$ & $\begin{array}{l}\text { Tumor } \\
\text { incidence (\%) }\end{array}$ & $\begin{array}{l}\text { Tumor } \\
\text { multiplicity }\end{array}$ \\
\hline Group I & I3 & 0 & 0 & 0 \\
Group II & I3 & I3 & 100 & 14 \\
Group III & I3 & 10 & 76.9 & 7.6 \\
Group IV & I3 & I2 & 92.3 & 8.4 \\
Group V & I3 & II & 84.6 & 6 \\
\hline
\end{tabular}

Note: ${ }^{a} n$ indicates the number of mice in each group. Abbreviation: DMBA, 7,12-dimethylbenz[a]anthracene. dermal layers, characterized by intense infiltration of inflammatory cells, increased acanthosis, squamous layer dysplasia, darkening of nucleus or hyperchromasia, stromal damage, loss of polarity, increase in cell size and mitotic activity, keratin pearl formation, and invasiveness, compared to the acetone-only-treated Group I animals (Figure 2B). Application of L. quinquestriatus venom in the antipromotion experimental groups (III-V) resulted in the reduction of these histological alterations, compared to Group II animals (Figure 2C-E).
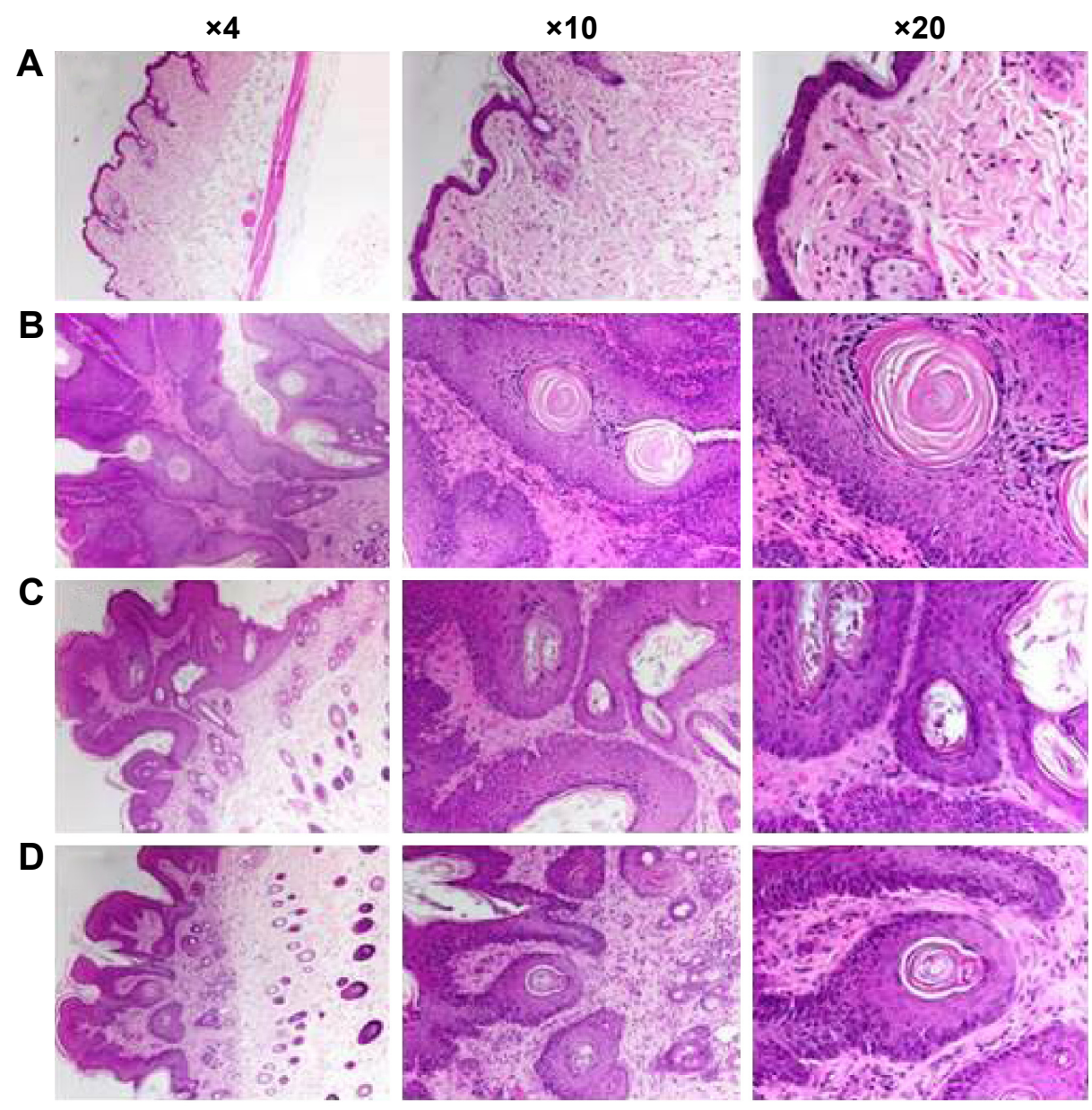

$\mathbf{E}$
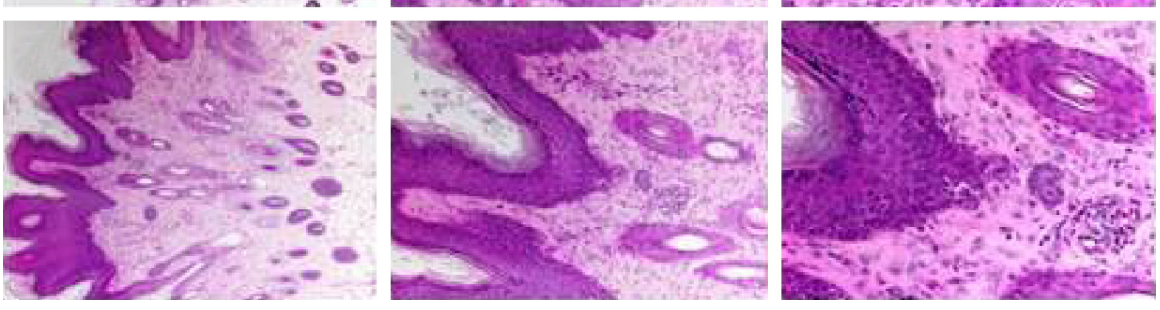

Figure 2 Effect of Leiurus quinquestriatus venom extract on histology of DMBA/croton oil-induced skin tumorigenesis.

Notes: Representative photomicrographs (magnification $\times 4, \times 10$, and $\times 20$ ) depicting histological changes are shown. (A) Group I: only vehicle $(0.2 \mathrm{~mL}$ acetone); (B) Group II: DMBA + croton oil; (C) Group III: DMBA + croton oil + L. quinquestriatus venom ( $17.5 \mu \mathrm{g}$ per mouse); (D) Group IV: DMBA + croton oil + L. quinquestriatus venom ( $35 \mu \mathrm{g}$ per mouse); and (E) Group V: DMBA + croton oil + L. quinquestriatus venom ( $52.5 \mu \mathrm{g}$ per mouse). Vehicle-treated animals show normal histological pattern (A), DMBA + croton oil-treated animals show intense histological deformities (B), and DMBA + croton oil + L. quinquestriatus venom-treated animals show suppressed histological changes (C-E). Abbreviation: DMBA, 7,12-dimethylbenz[a]anthracene. 


\section{Effect of $L$. quinquestriatus venom on TNF- $\alpha$, IL-I $\beta$, and IL- 6 levels}

The effects of $L$. quinquestriatus venom on the expression levels of the proinflammatory cytokines TNF- $\alpha$, IL-1 $\beta$, and IL-6 are shown in Figure 3. A significant $(P<0.001)$ increase in the level of proinflammatory cytokines was observed in Group II animals, compared to the acetone-alone-treated Group I animals. In the antipromotion experimental animals, application of $L$. quinquestriatus venom resulted in a remarkable reduction $(P<0.05, P<0.01$, and $P<0.001$, respectively, in Groups III-V) in the levels of these proinflammatory cytokines, while the reduction was nonsignificant in the case of TNF- $\alpha$ and IL- $1 \beta$ in Group III animals compared to Group II experimental animals.

\section{Effect of $L$. quinquestriatus venom on $\mathrm{Ki}-67, \mathrm{NF}-\kappa B, \mathrm{COX}-2, \mathrm{Bcl} 2$, and VEGF expression}

The effects of L. quinquestriatus venom extract on the expression of Ki-67, NF-кB, COX-2, Bcl2, and VEGF are shown in Figures 4-8, respectively. Brown color indicates the immunopositive staining for $\mathrm{Ki}-67, \mathrm{NF}-\kappa \mathrm{B}, \mathrm{COX}-2$, $\mathrm{Bcl} 2$, and VEGF, while light blue color indicates hematoxylin staining. A noticeable increase in the number of cells having positive staining of $\mathrm{Ki}-67, \mathrm{NF}-\kappa \mathrm{B}, \mathrm{COX}-2$, $\mathrm{Bcl}$, and VEGF was observed in the DMBA/croton oil-treated Group II animals compared to vehicle-alonetreated Group I control animals. Application of L. quinquestriatus venom extract in the antipromotion experimental groups (III-V) reduced the expression of $\mathrm{Ki}-67, \mathrm{NF}-\kappa \mathrm{B}$, COX-2, Bcl2, and VEGF compared with Group II animals (Figures 4-8).

\section{Discussion}

Cancer is one of the leading chronic human diseases that has a huge impact on human society due to lack of complete treatment options. Attention has been given to the search for naturally derived products with anticancer potential. In this study, we have investigated the in vivo anticancer potential of the venom extract from the
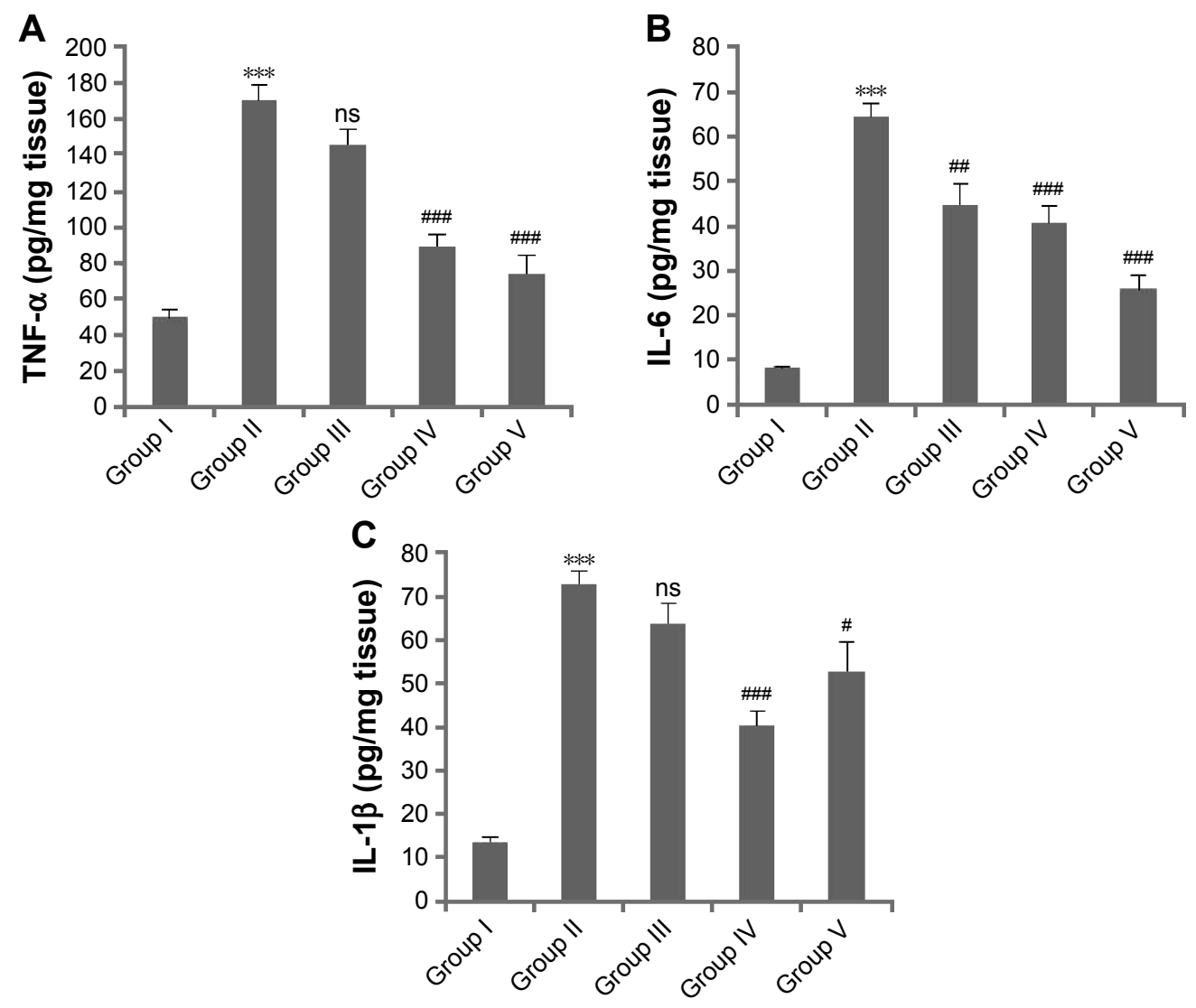

Figure 3 Effect of Leiurus quinquestriatus venom extract on DMBA/croton oil-induced cutaneous proinflammatory cytokines.

Notes: (A) TNF- $\alpha$; (B) IL-6; (C) IL-I $\beta$. Values are expressed as mean \pm SEM $(n=6)$. $* * * P<0.00$ I shows significant difference in DMBA + croton oil-treated Group II experimental animals compared with vehicle-treated Group I animals. ${ }^{P}<0.05, \# P<0.0$ I, and ${ }^{\# \#} P<0.00$ I show significant difference in the $L$. quinquestriatus venom-treated experimental animal groups (Groups III-V) compared with DMBA + croton oil-treated Group II animals. ns indicates nonsignificant reduction of TNF- $\alpha$ and IL-I $\beta$ levels in the animals of experimental Group III compared to Group II animals.

Abbreviations: DMBA, 7,12-dimethylbenz[a]anthracene; IL, interleukin; SEM, standard error of the mean; TNF, tumor necrosis factor. 


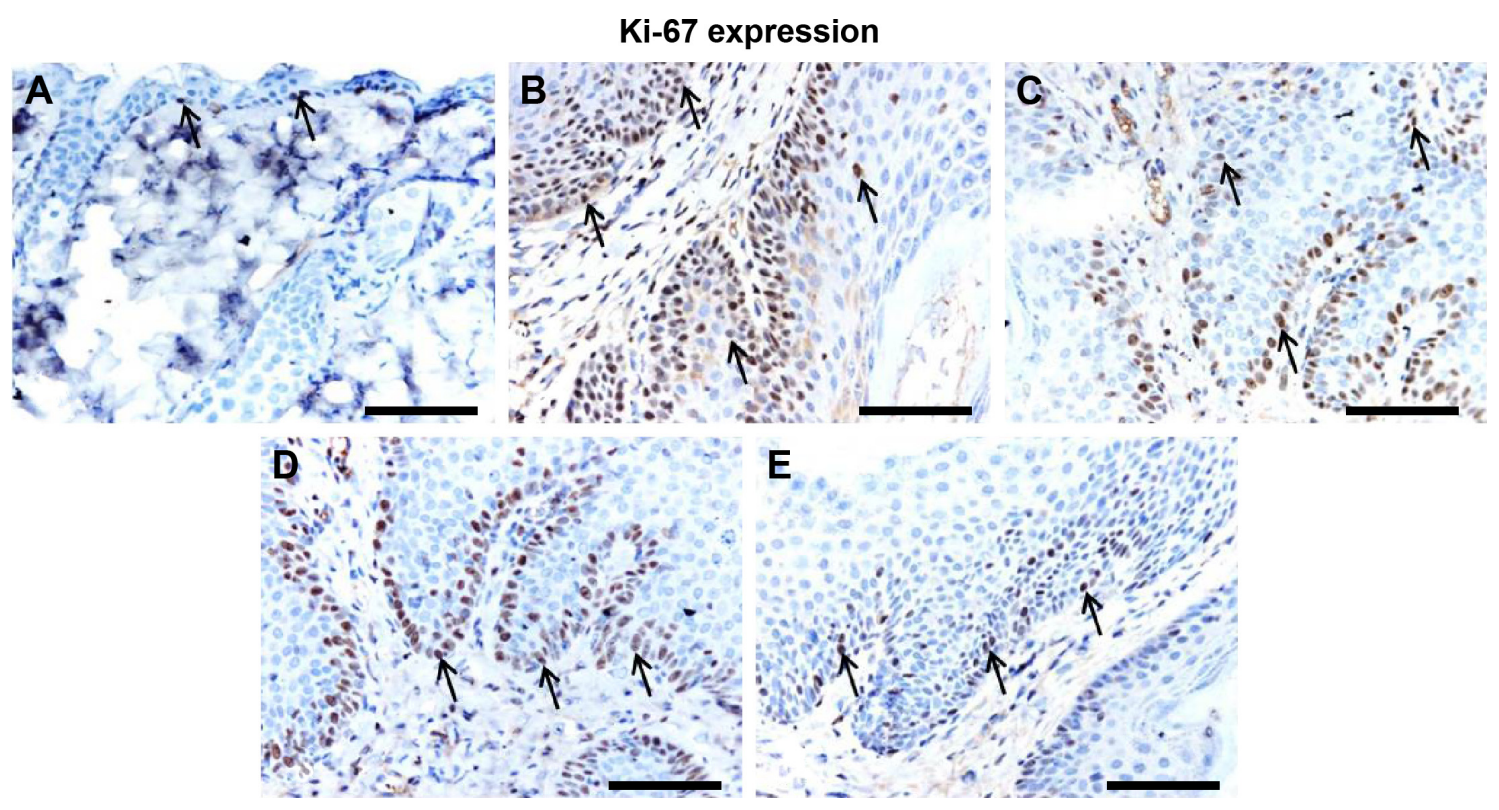

Figure 4 Effect of Leiurus quinquestriatus venom extract on cell proliferation marker Ki-67 in the chemically induced skin tumors.

Notes: Representative photomicrographs (magnification $\times 20$; scale bar: $100 \mu \mathrm{m})$ of $(\mathbf{A})$ Group I: only vehicle $(0.2 \mathrm{~mL}$ acetone); (B) Group II: DMBA + croton oil; (C) Group III: DMBA + croton oil + L. quinquestriatus venom (I7.5 $\mu \mathrm{g}$ per mouse); (D) Group IV: DMBA + croton oil + L. quinquestriatus venom (35 $\mu \mathrm{g}$ per mouse); and (E) Group V: DMBA + croton oil + L. quinquestriatus venom ( $52.5 \mu \mathrm{g}$ per mouse). Group Il animals showed more number and intense immunopositive staining of Ki-67 (arrows) compared with Group I animals. Groups containing L. quinquestriatus venom-treated animals exhibit reduced Ki-67 expression (arrows) compared to Group II animals. Abbreviation: DMBA, 7,12-dimethylbenz[a]anthracene.

L. quinquestriatus scorpion species. Scorpion venoms are composed of a number of biologically active constituents with promising anticancer potential. Though various findings have revealed that the anticancer property, ie, the ability to interfere with different pathways and molecules associated with carcinogenesis, of the scorpion venom is multifactorial, the exact underlying mechanism is not yet fully understood. ${ }^{9,16,27}$

Most of the research work on the anticancer potential of scorpion venoms is conducted on in vitro systems

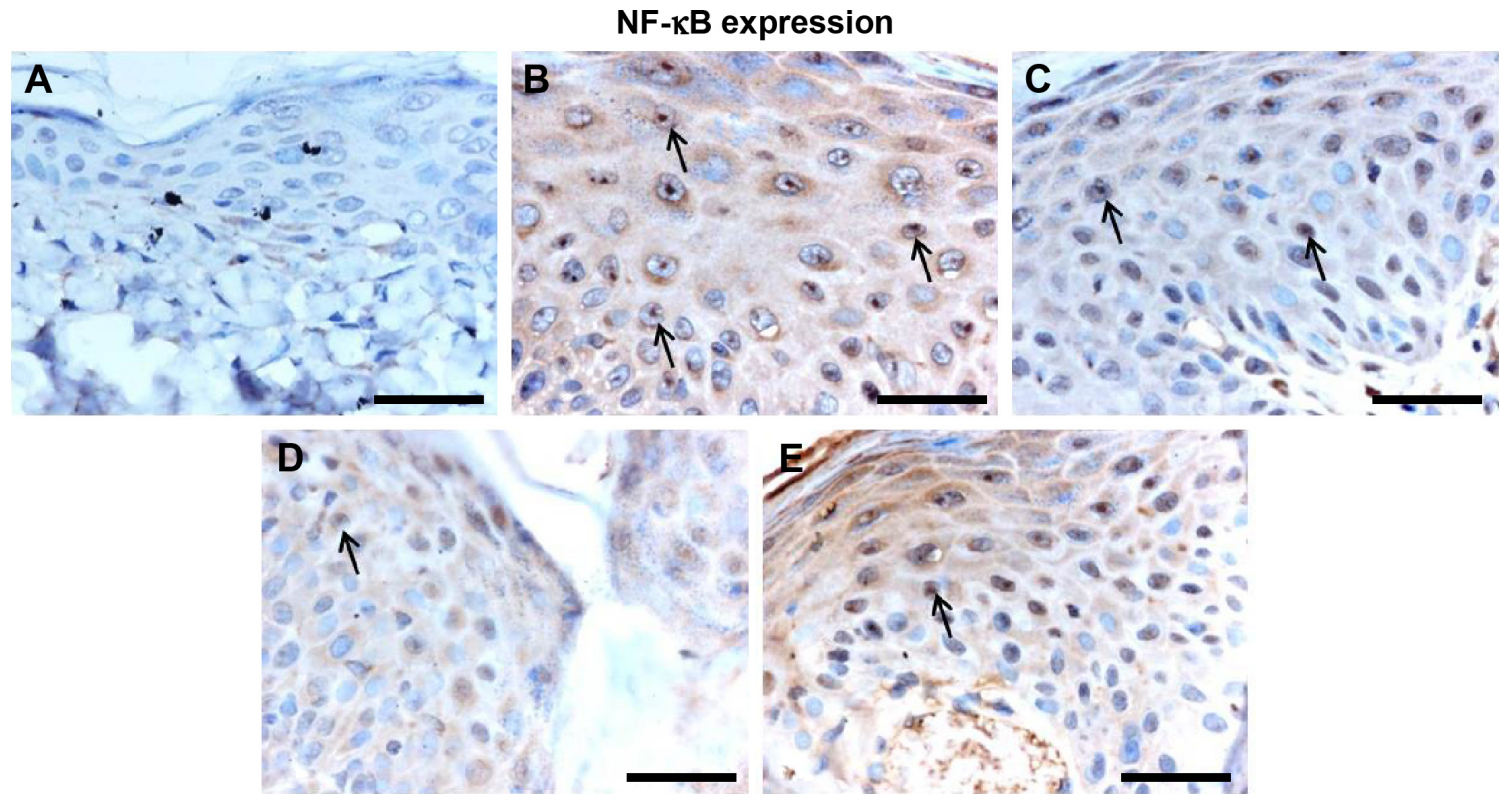

Figure 5 Effect of Leiurus quinquestriatus venom extract on NF- $\kappa B$ expression in chemically induced skin tumors.

Notes: Representative photomicrographs (magnification $\times 40$; scale bar: $50 \mu \mathrm{m})$. (A) Group I: only vehicle (0.2 mL acetone); (B) Group II: DMBA + croton oil; (C) Group III: $\mathrm{DMBA}+$ croton oil + L. quinquestriatus venom (I7.5 $\mu \mathrm{g}$ per mouse); (D) Group IV: DMBA + croton oil + L. quinquestriatus venom (35 $\mu g$ per mouse); and (E) Group V: $\mathrm{DMBA}+$ croton oil + L. quinquestriatus venom ( $52.5 \mu \mathrm{g}$ per mouse). Group II animals showed more immunopositive staining of NF-KB (arrows) compared with Group I animals. L. quinquestriatus venom-treated animals exhibit reduced NF- $\kappa B$ expression (arrows) compared to Group II animals.

Abbreviations: DMBA, 7,12-dimethylbenz[a]anthracene; NF- $\mathrm{BB}$, nuclear factor kappa-B. 


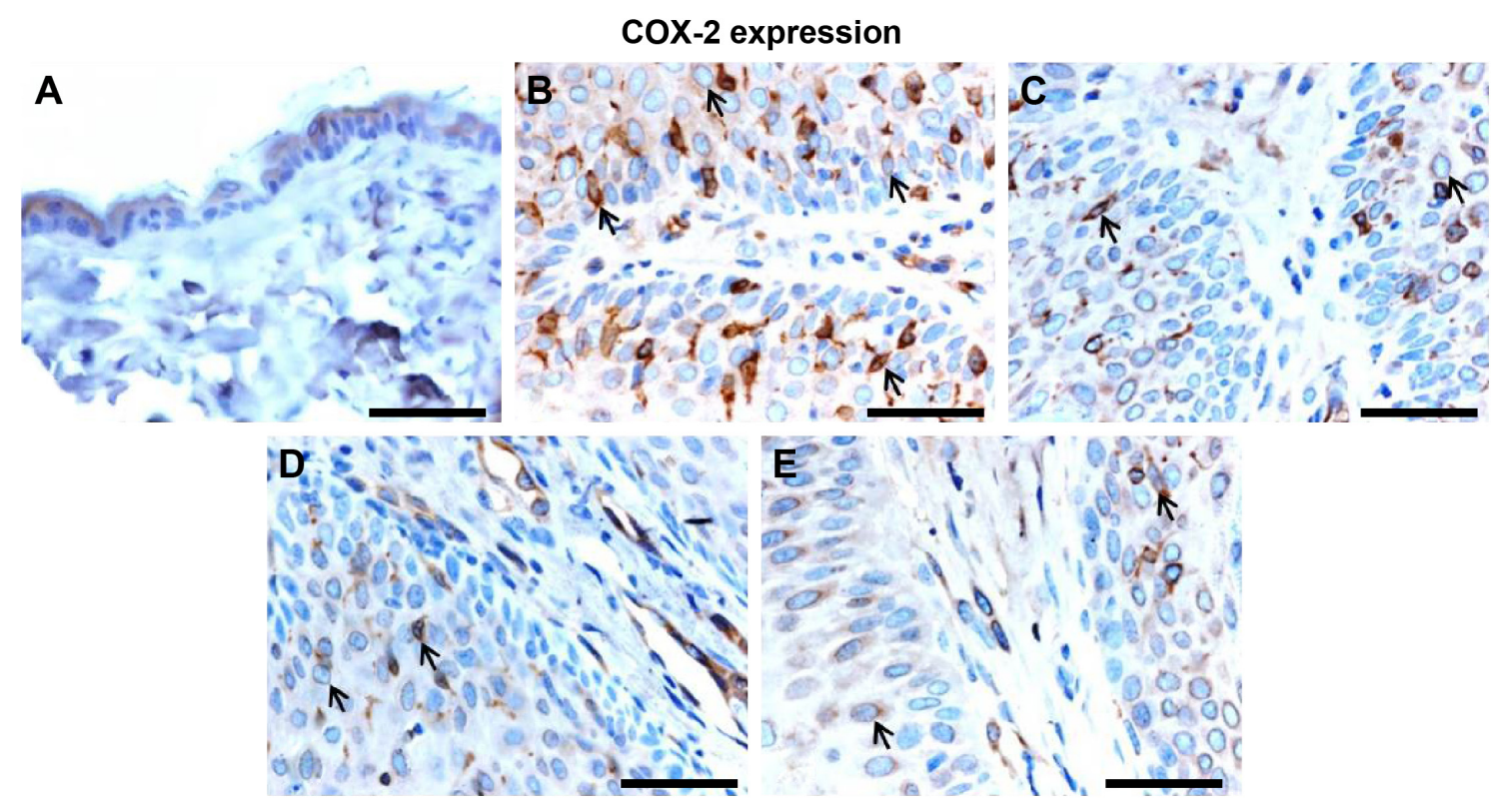

Figure 6 Effect of Leiurus quinquestriatus venom extract on COX-2 expression in chemically induced skin tumors.

Notes: Representative photomicrographs (magnification $\times 40$; scale bar: $50 \mu \mathrm{m})$. (A) Group I: only vehicle $(0.2 \mathrm{~mL}$ acetone); (B) Group II: DMBA + croton oil; (C) Group III: $\mathrm{DMBA}+$ croton oil + L. quinquestriatus venom (17.5 $\mu \mathrm{g}$ per mouse); (D) Group IV: DMBA + croton oil + L. quinquestriatus venom (35 $\mu \mathrm{g}$ per mouse); and (E) Group V: $\mathrm{DMBA}+$ croton oil + L. quinquestriatus venom ( $52.5 \mu \mathrm{g}$ per mouse). Group II animals showed more immunopositive staining of COX-2 (arrows) compared with Group I animals. L. quinquestriatus venom-treated animals exhibit reduced COX-2 expression (arrows) compared to Group II animals.

Abbreviations: COX, cyclooxygenase; DMBA, 7,12-dimethylbenz[a]anthracene.

and, for the first time (to the best of authors knowledge), we have investigated the in vivo anticancer potential of L. quinquestriatus venom against the classic two-stage mouse skin carcinogenesis model. Development of cancer is a complex and multistep process, which is critically associated with the progressive accretion of genetic and epigenetic changes. The findings of this study show that the topical application of $L$. quinquestriatus venom extract alleviates tumorigenesis and expression of different cancerpromoting markers.

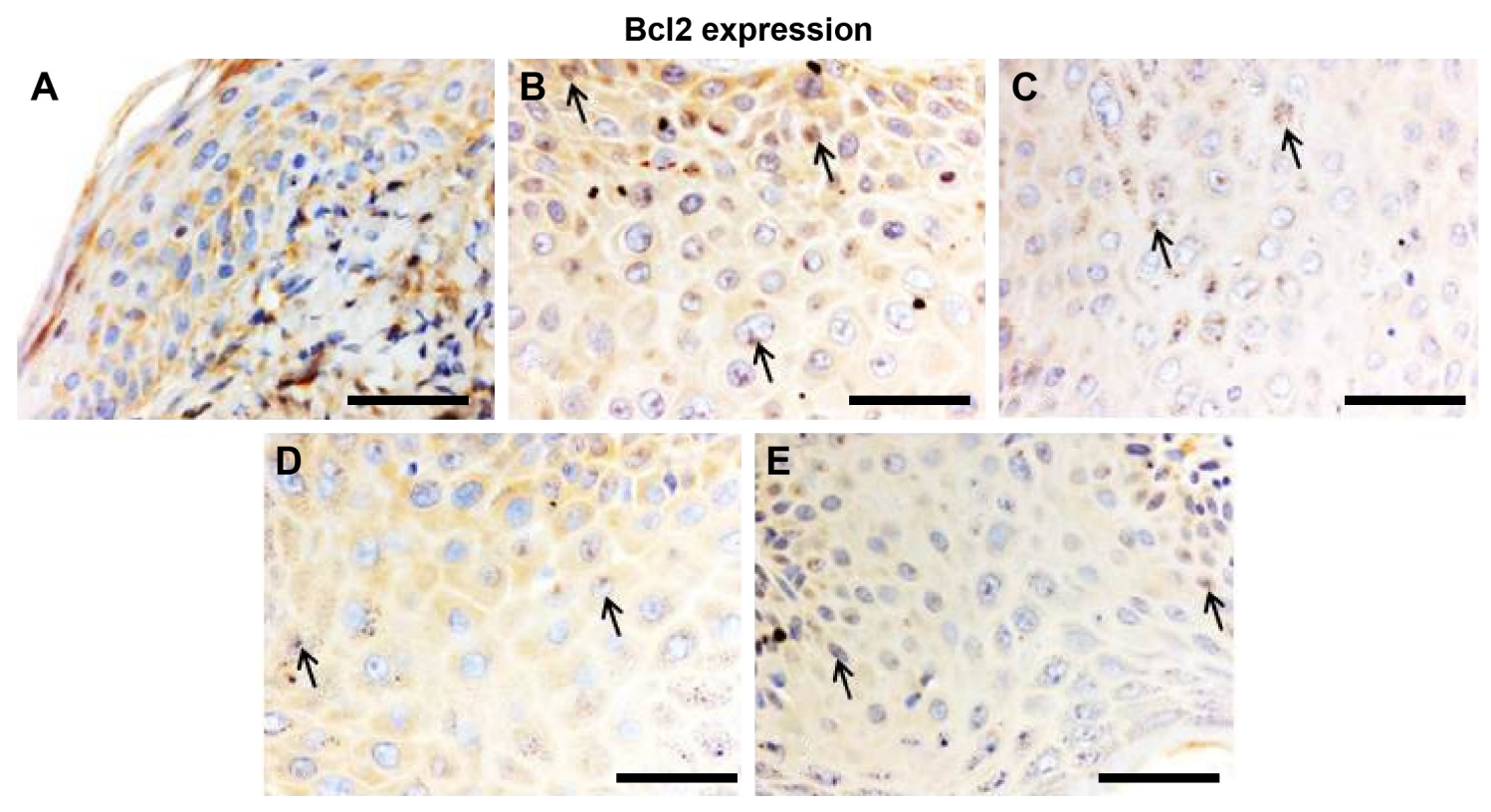

Figure 7 Effect of Leiurus quinquestriatus venom extract on Bcl2 expression in chemically induced skin tumors.

Notes: Representative photomicrographs (magnification $\times 40$; scale bar: $50 \mu \mathrm{m})$. (A) Group I: only vehicle $(0.2 \mathrm{~mL}$ acetone); (B) Group II: DMBA + croton oil; (C) Group III: $\mathrm{DMBA}+$ croton oil + L. quinquestriatus venom (I7.5 $\mu \mathrm{g}$ per mouse); (D) Group IV: DMBA + croton oil + L. quinquestriatus venom (35 $\mu \mathrm{g}$ per mouse); and (E) Group V: $\mathrm{DMBA}+$ croton oil + L. quinquestriatus venom ( $52.5 \mu \mathrm{g}$ per mouse). Group II animals showed more immunopositive staining of Bcl2 (arrows) compared with Group I animals. L. quinquestriatus venom-treated animal groups exhibit reduced Bcl2 expression (arrows) compared to Group II animals.

Abbreviations: Bcl2, B-cell lymphoma-2; DMBA, 7,12-dimethylbenz[a]anthracene. 


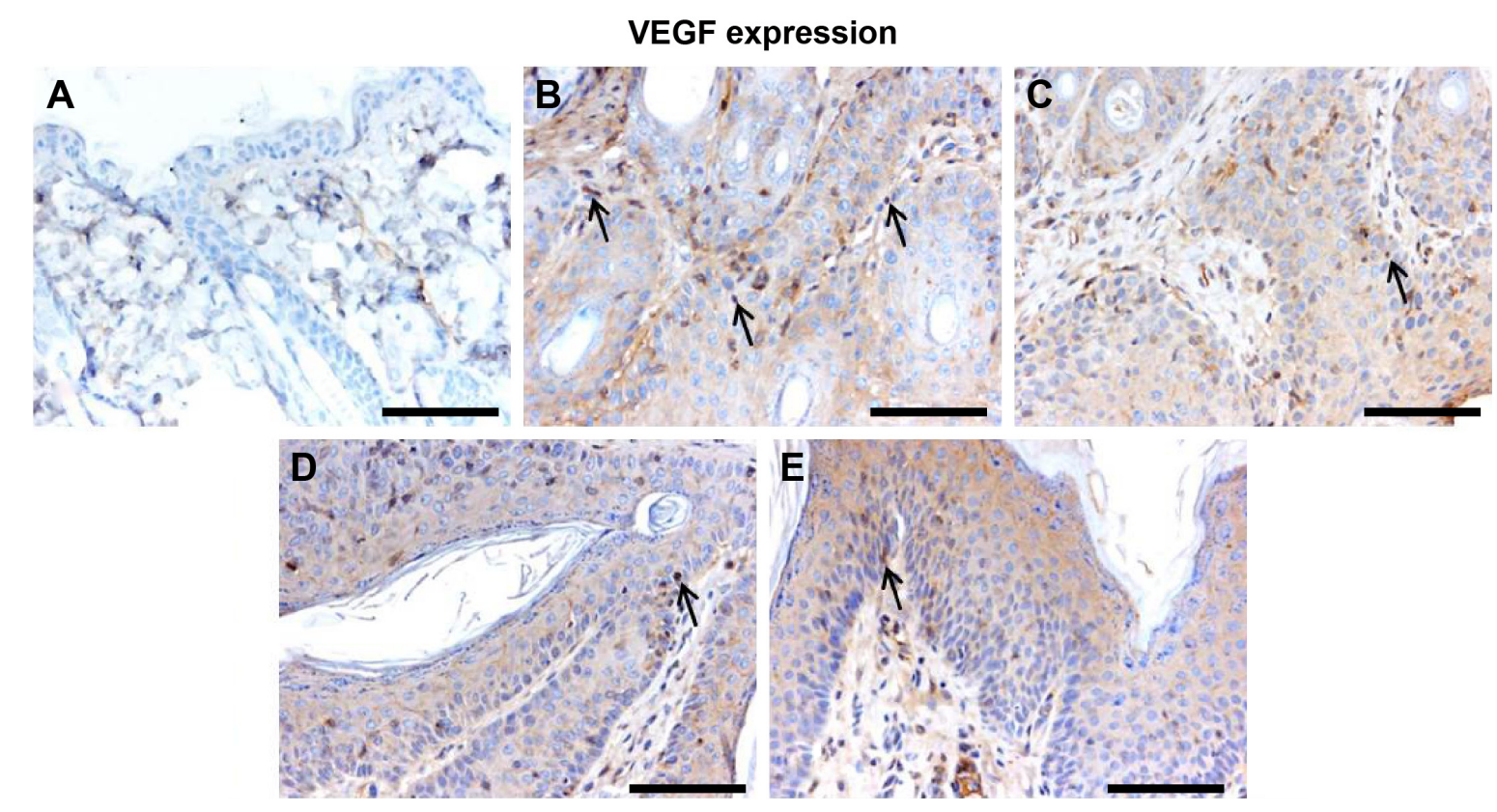

Figure 8 Effect of Leiurus quinquestriatus venom extract on VEGF expression in chemically induced skin tumors.

Notes: Representative photomicrographs (magnification $\times 20$; scale bar: $100 \mu \mathrm{m})$. (A) Group I: only vehicle $(0.2 \mathrm{~mL}$ acetone); (B) Group II: DMBA + croton oil; (C) Group III: DMBA + croton oil + L. quinquestriatus venom (17.5 $\mu \mathrm{g}$ per mouse); (D) Group IV: DMBA + croton oil + L. quinquestriatus venom (35 $\mu \mathrm{g}$ per mouse); and (E) Group V: DMBA + croton oil + L. quinquestriatus venom ( $52.5 \mu \mathrm{g}$ per mouse). Group II animals showed more immunopositive staining of VEGF (arrows) compared with Group I animals. L. quinquestriatus venom-treated animal groups exhibit reduced VEGF expression (arrows) compared to Group II animals.

Abbreviations: DMBA, 7,I2-dimethylbenz[a]anthracene; VEGF, vascular endothelial growth factor.

Uncontrolled cell proliferation, one of the hallmarks of cancer, is the main focus of current research to defeat cancer development. ${ }^{28}$ Previous findings have demonstrated that scorpion venom has remarkable inhibitory effects on cancer cell proliferation. ${ }^{916,29-31}$ Our findings of reduction in skin tumorigenesis and tumor multiplicity are in agreement with these reports and suggest that the venom of $L$. quinquestriatus has the potential to suppress cutaneous cell proliferation in the two-stage mouse skin tumorigenesis model by modulating the expression of the cell proliferation marker Ki-67. $\mathrm{Ki}-67$, an important protein of the nucleus, is expressed in different phases of the cell cycle (G1, S, G2, and M), with minimal or no expression in the resting or G0 phase. Its presence is critical for cell proliferation in carcinogenesis. ${ }^{32}$ Our findings of a reduced expression of Ki-67 in L. quinquestriatus venom-treated mice support its antiproliferative characteristics.

The anticarcinogenic potential of $L$. quinquestriatus venom extract was further supported by another finding of this study, which is the expression of $\mathrm{Bcl} 2 . \mathrm{Bcl} 2$ is one of the important proteins that play a vital role in cell proliferation, migration and cell invasion, and apoptosis. ${ }^{33-35} \mathrm{Bcl} 2$ not only helps in cellular proliferation but is also involved in the regulation of apoptosis. ${ }^{34}$ Inhibition of Bcl2 overexpression suggests the antitumorigenic potential of $L$. quinquestriatus venom. Our findings are in agreement with earlier reports that show the inhibitory action of scorpion venom on Bcl2 expression. ${ }^{36-38}$

The role of NF- $\kappa \mathrm{B}$ in the development of malignancies, including skin carcinoma, is well documented. ${ }^{39-41} \mathrm{NF}-\kappa \mathrm{B}$, a major transcription factor, also plays a vital role in cellular development, proliferation, apoptosis, and cell division. Considering the impact of NF- $\mathrm{KB}$ in tumorigenesis, we have investigated the effect of $L$. quinquestriatus venom on cutaneous NF- $\mathrm{kB}$ activation. Our findings demonstrate that L. quinquestriatus venom inhibits NF- $\mathrm{\kappa B}$ activation, which predicts the anticarcinogenic nature of the venom. Previous research regarding the effect of scorpion venom on NF- $\kappa B$ activation supports our result. ${ }^{31}$ A number of reports reveal that venom extracted from arthropods and other animals plays a vital role in the management of various chronic inflammatory diseases, such as rheumatoid arthritis, atherosclerosis, and cancer, through immunosuppression via modulating the expression of different inflammatory mediators, such as NF- $\mathrm{KB}, \mathrm{COX}-2$, INOS, cytokines, and so on. ${ }^{42-46}$ The polypeptide venom extract from $L$. quinquestriatus further shows its immunosuppressive potential by inhibiting the expression of NF- $\mathrm{\kappa B}$ target genes encoding COX-2 and proinflammatory cytokines (TNF- $\alpha$, IL6, and IL-1 $\beta$ ). Previous findings have also revealed that scorpion venom attenuated the aggressiveness of malignancy by modulating the expression of cytokines and COX-2. ${ }^{47,48}$ Another finding of this study is the 
inhibitory effect of L. quinquestriatus venom extract on the expression of VEGF, which further supports its anticancer potential. VEGF is an important glycoprotein that plays a crucial role in tumor angiogenesis, one of the hallmarks of malignancy. ${ }^{49,50}$ VEGF signaling also plays a vital role in the growth and survival of endothelial cells, as well as cancer cell migration. ${ }^{50}$ Earlier reports also demonstrate that scorpion venom extracts and toxins have suppressed the extent of malignancy and neovascularization by modulation of the signaling molecules associated with angiogenesis. ${ }^{51-53}$

Histological findings reveal that the animals of the vehicle-treated control group showed a normal pattern of skin epidermal and dermal layers, with mild or no infiltration of inflammatory cells. Animals of the DMBA-croton oil-treated group exhibited massive changes, characterized by intense infiltration of inflammatory cells, increased acanthosis, squamous layer dysplasia, darkening of nucleus or hyperchromasia, stromal damage, loss of polarity, increase in size, mitotic activity, keratin pearl formation, and invasiveness, in both epidermal and dermal layers. Application of L. quinquestriatus scorpion venom suppressed these histological alterations, indicating the attenuation potential of the venom. These findings corroborated with the histological data. Furthermore, the effect of scorpion venom on tumor incidence and gross tumor multiplicity reveals its antitumorigenic potential. One of the limitations of this study is that the median dose of L. quinquestriatus scorpion venom did not show dose-dependent inhibitory effect on the phenotypic tumor characteristics in terms of tumor incidence and tumor multiplicity, which probably may be due to the single or cumulative effects of a number of factors (genetic, epigenetic, environmental, and so on).

In conclusion, the findings of this study demonstrate that the venom extract from L. quinquestriatus scorpion species possesses antitumorigenic potential. Additional studies are warranted to further elucidate the signaling mechanisms underlying the in vivo antitumorigenic action of scorpion venom.

\section{Acknowledgments}

The authors thank the Research Centre of Prince Sultan Military Medical City and King Abdulaziz City for Science and Technology for providing the necessary facilities and financial support. Thanks are due to Mr Rajamohammed Abbas Manthiri and Mr Nasreddien M Abdo Osman for milking and processing the venom. Scientific inputs and critical editing of the manuscript by Dr Mohammed Arshaduddin is gratefully acknowledged.

\section{Disclosure}

The authors report no conflicts of interest in this work.

\section{References}

1. Torre LA, Bray F, Siegel RL, Ferlay J, Lortet-Tieulent J, Jemal A. Global cancer statistics, 2012. CA Cancer J Clin. 2015;65(2):87-108.

2. Urruticoechea A, Alemany R, Balart J, Villanueva A, Vinals F, Capella G. Recent advances in cancer therapy: an overview. Curr Pharm Des. 2010;16(1):3-10.

3. Palumbo MO, Kavan P, Miller W, et al. Systemic cancer therapy: achievements and challenges that lie ahead. Front Pharmacol. 2013;4:57.

4. Liberio MS, Joanitti GA, Fontes W, Castro MS. Anticancer peptides and proteins: a panoramic view. Protein Pept Lett. 2013;20(4):380-391.

5. Demain AL, Vaishnav P. Natural products for cancer chemotherapy. Microb Biotechnol. 2011;4(6):687-699.

6. Newman DJ, Cragg GM. Natural products as sources of new drugs from 1981 to 2014. J Nat Prod. 2016;79(3):629-661.

7. Tyagi N, Tyagi M, Pachauri M, Ghosh PC. Potential therapeutic applications of plant toxin-ricin in cancer: challenges and advances. Tumor Biol. 2015;36(11):8239-8246.

8. Chaisakul J, Hodgson WC, Kuruppu S, Prasongsook N. Effects of animal venoms and toxins on hallmarks of cancer. J Cancer. 2016;7(11): 1571-1578.

9. Ding J, Chua P-J, Bay B-H, Gopalakrishnakone P. Scorpion venoms as a potential source of novel cancer therapeutic compounds. Exp Biol Med. 2014;239(4):387-393.

10. Vyas VK, Brahmbhatt K, Bhatt H, Parmar U. Therapeutic potential of snake venom in cancer therapy: current perspectives. Asian Pac J Trop Biomed. 2013;3(2):156-162.

11. Heinen TE, da Veiga ABG. Arthropod venoms and cancer. Toxicon. 2011;57(4):497-511.

12. Stockmann R, Ythier E, Flay N. Scorpions of the World. NAP editions ed. France: Verrières-leBuisson; 2010.

13. Al Asmari AK, Al Zahrani AG, Al Jowhary S, Arshaduddin M. Clinical aspects and frequency of scorpion stings in the Riyadh Region of Saudi Arabia. Saudi Med J. 2012;33(8):852-858.

14. Rochat H, Bernard P, Couraud F. Scorpion toxins: chemistry and mode of action. Adv Cytopharmacol. 1979;3:325-334.

15. Goudet C, Chi CW, Tytgat J. An overview of toxins and genes from the venom of the Asian scorpion Buthus martensi Karsch. Toxicon. 2002;40(9):1239-1258.

16. Gomes A, Bhattacharjee P, Mishra R, Biswas AK, Dasgupta SC, Giri B. Anticancer potential of animal venoms and toxins. Indian J Exp Biol. 2010;48(2):93-103.

17. Shao J, Kang N, Liu Y, Song S, Wu C, Zhang J. Purification and characterization of an analgesic peptide from Buthus martensii Karsch. Biomed Chromatogr. 2007;21(12):1266-1271.

18. Ramírez-Carreto S, Jiménez-Vargas JM, Rivas-Santiago B, et al. Peptides from the scorpion Vaejovis punctatus with broad antimicrobial activity. Peptides. 2015;73:51-59.

19. Cao L, Dai C, Li Z, et al. Antibacterial activity and mechanism of a scorpion venom peptide derivative in vitro and in vivo. PLoS One. 2012;7(7):e40135.

20. Zeng X-C, Zhou L, Shi W, et al. Three new antimicrobial peptides from the scorpion Pandinus imperator. Peptides. 2013;45:28-34.

21. El-Bitar AM, Sarhan MM, Aoki C, et al. Virocidal activity of Egyptian scorpion venoms against hepatitis C virus. Virol J. 2015;12(1):47.

22. Chen Y, Cao L, Zhong M, et al. Anti-HIV-1 activity of a new scorpion venom peptide derivative Kn2-7. PLoS One. 2012;7(4):e34947.

23. Ortiz E, Gurrola GB, Schwartz EF, Possani LD. Scorpion venom components as potential candidates for drug development. Toxicon. 2015;93:125-135.

24. Biswas A, Gomes A, Sengupta J, Datta P, Singha S, Dasgupta AK, Gomes A. Nanoparticle-conjugated animal venom-toxins and their possible therapeutic potential. J Venom Res. 2012;3:15-21. 
25. Khan AQ, Khan R, Tahir M, et al. Silibinin inhibits tumor promotional triggers and tumorigenesis against chemically induced two-stage skin carcinogenesis in Swiss albino mice: possible role of oxidative stress and inflammation. Nutr Cancer. 2014;66(2):249-258.

26. Majed F, Rashid S, Khan AQ, et al. Tannic acid mitigates the DMBA croton oil-induced skin cancer progression in mice. Mol Cell Biochem. 2015;399(1-2):217-228.

27. Ojeda PG, Wang CK, Craik DJ. Chlorotoxin: structure, activity and potential uses in cancer therapy. Peptide Sci. 2016;106(1):25-36.

28. Hanahan D, Weinberg RA. The hallmarks of cancer. Cell. 2000;100(1): 57-70.

29. Omran MAA. In vitro anticancer effect of scorpion Leiurus quinquestriatus and Egyptian cobra venom on human breast and prostate cancer cell lines. J Med Sci. 2003;3(1):66-86.

30. Zhang YY, Wu LC, Wang ZP, et al. Anti-proliferation effect of polypeptide extracted from scorpion venom on human prostate cancer cells in vitro. J Clin Med Res. 2009;1(1):24.

31. Song X, Zhang G, Sun A, et al. Scorpion venom component III inhibits cell proliferation by modulating NF- $\mathrm{\kappa B}$ activation in human leukemia cells. Exp Ther Med. 2012;4(1):146-150.

32. Healy E, Angus B, Lawrenck C, Rees J. Prognostic value of Ki67 antigen expression in basal cell carcinomas. Br J Dermatol. 1995;133(5): 737-741.

33. Koehler BC, Scherr A-L, Lorenz S, et al. Beyond cell death antiapoptotic bcl-2 proteins regulate migration and invasion of colorectal cancer cells in vitro. PLoS One. 2013;8(10):e76446.

34. Bonnefoy-Berard N, Aouacheria A, Verschelde C, Quemeneur L, Marçais A, Marvel J. Control of proliferation by Bcl-2 family members. Biochim Biophys Acta. 2004;1644(2):159-168.

35. Bélanger S, Côté M, Lane D, L'Espérance S, Rancourt C, Piché A. $\mathrm{Bcl}-2$ decreases cell proliferation and promotes accumulation of cells in $\mathrm{S}$ phase without affecting the rate of apoptosis in human ovarian carcinoma cells. Gynecol Oncol. 2005;97(3):796-806.

36. Li W, Li Y, Zhao Y, Yuan J, Mao W. Inhibition effects of scorpion venom extracts (Buthus matensii karsch) on the growth of human breast cancer MCF-7 cells. Afr J Tradit Complement Altern Med. 2014; 11(5):105-110.

37. Díaz-García A, Morier-Díaz L, Frión-Herrera Y, et al. In vitro anticancer effect of venom from Cuban scorpion Rhopalurus junceus against a panel of human cancer cell lines. J Venom Res. 2013;4:5.

38. Gupta SD, Gomes A, Debnath A, Saha A, Gomes A. Apoptosis induction in human leukemic cells by a novel protein Bengalin, isolated from Indian black scorpion venom: through mitochondrial pathway and inhibition of heat shock proteins. Chem Biol Interact. 2010; 183(2):293-303.
39. Xia Y, Shen S, Verma IM. NF- $\kappa B$, an active player in human cancers. Cancer Immunol Res. 2014;2(9):823-830.

40. Gasparini C, Celeghini C, Monasta L, Zauli G. NF-кB pathways in hematological malignancies. Cell Mol Life Sci. 2014;71(11):2083-2102.

41. Kim C, Pasparakis M. Epidermal p65/NF- $\kappa \mathrm{B}$ signalling is essential for skin carcinogenesis. EMBO Mol Med. 2014;6(7):970-983.

42. Gomes A, Alam MA, Bhattacharya S, et al. Ethno biological usage of zoo products in rheumatoid arthritis. Indian J Exp Biol. 2011;49(8): 565-573.

43. Ahmadi M, Zare Mirakabadi A, Hashemlou M, Hejazi M. Study on anti inflammatory effect of scorpion (Mesobuthus eupeus) venom in adjuvantinduced arthritis in rats. Archives of Razi. 2009;64(1):51-56.

44. Ahluwalia S, Shah N. Animal venom for treating breast cancer. Int $J$ Pharm Pharmaceut Sci. 2014;6(9):24-30.

45. Park HJ, Lee HJ, Choi MS, et al. JNK pathway is involved in the inhibition of inflammatory target gene expression and NF-kappaB activation by melittin. J Inflamm. 2008;5(1):1.

46. Dkhil M, Abdel-Baki A, Al-Quraishi S, Al-Khalifa M. Anti-inflammatory activity of the venom from samsum ants Pachycondyla sennaarensis. Afr J Pharm Pharmacol. 2010;4(3):115-118.

47. Zhang Y-Y, Zhang W-D, Qin J. Polypeptide extract from scorpion venom(PESV)downregulates the expression of COX-2 and MMP-9 in DU-145 cell lines. Prog Modern Biomed. 2006;6(5):8-10.

48. Zhang W-D, Zhang Y-Y, Wang Z-X, Wang Z-P, Jia Q. Effect of polypeptide extract from scorpion venom on tumor growth and cellular immunity in rats with W256 sarcocarcinoma. J Shandong Univ. 2007;3:018

49. Carmeliet P. VEGF as a key mediator of angiogenesis in cancer. Oncology. 2005;69(suppl 3):4-10.

50. Hicklin DJ, Ellis LM. Role of the vascular endothelial growth factor pathway in tumor growth and angiogenesis. J Clin Oncol. 2005; 23(5):1011-1027.

51. Sui W, Zhang W, Wu L, et al. [Study on the mechanism of polypeptide extract from scorpion venom on inhibition of angiogenesis of $\mathrm{H} 22$ hepatoma]. Zhongguo Zhong Xi Yi Jie He Za Zhi. 2014;34(5):581-586. Chinese.

52. Sun X, Zhang Y, Jia Q, Wang Z, Zhang W. [Effect of polypeptide extract from scorpion venom (PESV) with chemotherapy inhibited angiogenesis of Lewis lung carcinomas]. Zhongguo Zhong Yao Za Zhi. 2011;36(12):1644-1649. Chinese.

53. Erdogan A, Schaefer CA, Schaefer M, et al. Margatoxin inhibits VEGFinduced hyperpolarization, proliferation and nitric oxide production of human endothelial cells. J Vasc Res. 2005;42(5):368-376.
Drug Design, Development and Therapy

\section{Publish your work in this journal}

Drug Design, Development and Therapy is an international, peerreviewed open-access journal that spans the spectrum of drug design and development through to clinical applications. Clinical outcomes, patient safety, and programs for the development and effective, safe, and sustained use of medicines are the features of the journal, which

\section{Dovepress}

has also been accepted for indexing on PubMed Central. The manuscript management system is completely online and includes a very quick and fair peer-review system, which is all easy to use. Visit http://www.dovepress.com/testimonials.php to read real quotes from published authors. 